\title{
Mental chronometry in officer involved shootings
}

\begin{abstract}
Mental chronometry, or the examination of the time it takes a human to perceive and react to a stimulus, has been studied by researchers for more than a century. The reaction time to commence and cease shooting a firearm varies to some extent by individual and is impacted by internal psychological and physiological aspects of the person and by external environmental factors. Public safety officers and others, such as combat-deployable military personnel, must be cognizant of the factors affecting high-stakes decision-making and reactionary threat response. This extends to the design of training programs, the development of comprehensive policy regarding force usage and defensive tactics, and the necessary knowledge for after action investigation of such events. While the psychological literature is robust on the issue of attention and mental chronometry, public safety trainers and the curriculums in law enforcement recruit academies have not adequately expanded topics to explain the relevance for law enforcement officers. Because of this gap within the criminal justice literature, the paper does not focus solely on previous research evidence.
\end{abstract}

Keywords: reaction time (rt), perceptual distortion, inattention blindness (ib), defensive tactics
Volume 4 Issue 3 - 2017

\author{
Richard M Hough \\ College of Education and Professional Studies, University of \\ West Florida, USA
}

\begin{abstract}
Correspondence: Richard M Hough, College of Education and Professional Studies, University of West Florida, I 1000 University Parkway, Pensacola, FL, USA 325I4, Tel (+I) 850-8576413,Email rhough@uwf.edu
\end{abstract}

Received: February 23, 2017 | Published: April 03, 2017

\section{Introduction}

A touchstone of performance in most sports activities is reaction time (RT). Axiomatic is that reaction following action. In high-stakes threat assessment and response by law enforcement officers and combat deployed military personnel, reaction time to a potentially lethal threat may carry grave consequences. It is frequently the case that the dynamics surrounding response to threat may be chaotic and fast-moving. Humans process information coming to them through the senses in stages that involve identifying the stimulus, selecting a response, and taking action. This process is lengthened and made more complex based on how many sources and how much information is presented as well as by the number of potential response options, among other things. This latter issue of multiple response options is known as Hicks Law. ${ }^{1}$ For the law enforcement officer or combat deployed military member, expedient response selection can be critical when confronting threats. As to law enforcement choice selection among force options, the U.S. Supreme Court properly realized that the hindsight available after lengthy consideration of what might be done does not reflect the reality of an officer on the scene: "The calculus of reasonableness must embody allowance for the fact that police officers are often forced to make split-second judgments- in circumstances that are tense, uncertain, and rapidly evolving -- about the amount of force that is necessary in a particular situation". ${ }^{2}$ Reaction time measured against the potential for calamity may seem slow indeed, even if the increments are seconds or less. A jury or a judge, as trier of fact, may ultimately be asked to determine if an officer acted as other officers would have under similar conditions. Explanations of the dynamics of mental chronometry as well as perceptual distortion during an event and in subsequent recall of that event may help inform a jury's decision. ${ }^{3}$

An officer may fail to perceive a threat and thus be attacked and possibly killed. An officer may also perceive the threat and begin to respond with the same outcome of suffering injury or death. An officer who perceives the threat and reacts in a way and with sufficient time to employ deadly force against the threat may still be injured or killed while confronting the threat. In rare instances, an officer may also perceive a threat where none actually exists and yet respond with deadly force that results in the injury or death of the incorrectly identified threat. The individual who threatens an officer with a deadly weapon, or who is mistakenly perceived as a threat by the officer, may be in motion. One or more of the person's limbs, his head, and his hands may be creating multiple points of attention that the human officer must attempt to perceive rapidly and accurately for threat or signal of threat. In many such instances an officer may be said to be behind the curve in responding to the threat he now perceives. Some instances result in an officer discharging his firearm while a threat faces him. Alternately, the threat may brandish a firearm or even fire at the officer, and immediately turn to flee or seek cover. In fact, a subject may fire over his own shoulder or while obliquely reaching back while simultaneously trying to run away. Such dynamics can result in a lawfully fired projectile striking the threat subject in the side or the back. An officer may fire intentionally properly and rapidly considering (even with some level of automaticity) the threat as one requiring greater attentional resources than the microsecond to second positioning in space of the threat's anatomy. The officer may also pull the trigger as the end task in a functional chain of the brain's instruction to fire, only to lag behind the threat in the process of turning away and thus being struck somewhere other than anterior center mass.

\section{Discussion}

Law enforcement officers when perceiving a deadly threat may respond using deadly force. Tragically, it is sometimes learned after the fact than an individual may not have possessed, for instance, a firearm. Nevertheless, the perception of threat may set in motion the officers lethal force response. An officer's actions during this type of event are evaluated under the U.S. Supreme Court's decision in 
the Graham v. Connor. ${ }^{2}$ This case utilizes the Fourth Amendment and a standard of "objective reasonableness" to evaluate whether a specific officer acted in a way that similarly situated adequately trained officers would have acted. The decision may occur in well less than a second ${ }^{4}$ followed by the muscles activating to extricate a firearm from a safety holster, raise the firearm into position, aim the weapon and pull the trigger. Reaction time understood in this way while conceptually easier to examine, nonetheless occurs in brief moments with potentially no opportunity for reflection prior to the sequence concluding. The layperson may think of reaching for a hot object and realizing that the object will be too hot to touch yet not being able to stop the grasp of the object until it is too late. Similarly, many have experienced closing a door while simultaneously realizing an appendage would be struck by that door yet being unable to cease the action in time to avoid the pinch.

Initial questions of wounds of the posterior or dorsal portion of the coronal plane are often not readily understood by laypersons, including media representatives, or many investigative or judicial personnel. Such injuries may be the logical result of the previously discussed reaction or response to a perceived threat. Given the extensive research over time, and the improvements in technology, accurate measurement of brain activity and reactions have greatly improved. ${ }^{5}$ In the 2013 officer involved shooting guidelines published by the International Association of Chiefs of Police (IACP) and ratified by that organization's Police Psychological Services Section, investigators and administrators are admonished to become educated on human performance factors implicated in force confrontations. ${ }^{6}$ While extensive and ongoing training may improve the sequential activity of threat identification and assessment, force selection-response, and the dimensions of speed and accuracy, the reaction of a human officer will likely still lag behind the perceived initiating threat. Eliminating all risk of errors in deadly force decisions by officers is not likely given the fear response and other factors generated by a perceived deadly threat. ${ }^{7}$ Numerous combinations of neuropsychological interactions combine during urgent decision-making tasks to create potential trade-offs between speed of response and accuracy of that response. ${ }^{8}$ Advances in understanding the role of subliminal processes of the brain inform our understanding of decisions made in all manner of circumstances including those that must be made quickly and with potentially deadly consequences. ${ }^{9}$ In contemplating the segments of a stimulus-response event that involves the employment of deadly force by an officer, there may be after-the-fact question or criticism based in part on injuries to a subject. One category of event that results in subject injuries is an individual who an officer perceives as presenting with a firearm pointed at the officer or an innocent other, coming into position to point and shoot, or reaching for such a weapon. In response to the perceived threat, the officer draws his own firearm and shoots at the threat. Training provides an important baseline of knowing what responses the officer may select, and acquiring some facility in the response options (e.g., drawing and firing a weapon, using physical control techniques, or taking cover). Gladwell's observation regarding decision-making conditions is apt: "How good people's decisions are under the fast-moving, high-stress conditions of rapid cognition is a function of training and rules and rehearsal". ${ }^{10}$ Even with training hours provided, the human officer's ability to improve reaction time has limits. ${ }^{11}$

\section{Policy and training}

The rules must reflect the conceptual as well as the physical limitations of the human officer. If the officer fails to initially perceive a threat, his reaction will be delayed. In fact, even if he correctly identifies a threat his reaction will not be simultaneous to the presentation of that threat. The officer may focus on one potential threat and in so doing miss the presence of another threat either because of the tunneling effect of complete focus on the former or the unexpected or novel nature of the latter. ${ }^{12}$ Agency policy (as well as training) must be informed by the recognition of psychological and physiological factors involving reactions to perceived threat. Training of officers must similarly include extensive discussion of these factors to assist officers in preparing mentally and in an ongoing fashion to respond as effectively as possible within human limits. Cessation of action, such as stopping pulling a trigger, is itself an action dependent on conclusion of the previous response (pulling the trigger). ${ }^{13}$ The limits of the human officer are often at odds with reacting in time to counter a deadly threat. ${ }^{14}$ Gavin de Becker wrote persuasively in his 1997 book The Gift of Fear about the role intuition plays in how we interpret threats in the world around us. With overt discussion during training classes of how we increase awareness of the signals in our environment, notably those given off by other humans, officers are enabled and arguably maintain a higher level of sensitivity to threat than the average citizen. This is true as well of combat-deployed military members whose lives may also depend on the moment-tomoment "reading" of people and situations. An officer's training emphasizes situational awareness and his experience enhances this as well as the understanding of spontaneous attack and limited or absent precursor signals. Color schemes are used to signify awareness levels and consequent behavior if sensory input reaches overwhelming levels. Explanation of the roots of intuition ${ }^{15}$ is important in the training of officers and military members who face dangerous situations and people. Defensive tactics and force training should also include discussion of the potential psychological/perceptual impact of high stress threat situations. ${ }^{16}$

\section{Perceptual distortion}

It is more common than not that law enforcement officers experience perceptual distortion during deadly force events. ${ }^{17}$ Perceptual distortion may affect memory. Lack of clarity or certainty of event sequence or content may present as dissembling to an uninformed observer or investigator or supervisor tasked with investigation of or review of a force usage. It is not uncommon for officers or combat soldiers to experience temporal, auditory, or attentional disruptions that preclude full and complete description of events even from the "single lens" perspective or vantage point of the individual. ${ }^{18}$ Chemicals rapidly entering the bloodstream in a state of physiological hyper-arousal will have an impact on sensory perception. ${ }^{19}$ A predictable outcome of perceptual distortions is an impact on memory and recall. ${ }^{20}$ The attention-memory connection has benefitted from increased research efforts largely within the psychological research community. Research into the ramifications of human limits of attention has examined a number of areas of human performance. There has been a great deal of study and research regarding distractions and how they can impact driving safety. ${ }^{21}$ In a similar vein, distractions in the operating room can result in adverse outcomes for patients..$^{22}$ Law enforcement training programs and manuals address observational skills and factors such as stress which affect an officer's perception. ${ }^{23}$ The potential compromising of officer safety is ever present when there is a failure to observe some action or misjudging movement and behaviors of individuals the officer is interacting with or who may be on the periphery of an officer's activity. Visual and cognitive attentions are impacted by a 
variety of factors. Sound, size, color, and intensity, among others, can draw initial attention, though over-stimulation may reduce such environmental signals to noise and compromise their ability to serve as warnings of danger. For the law enforcement officer, the ability to distinguish relevant from irrelevant input is critical. ${ }^{24}$ Add to this, issues of recognition errors such as identifying left or right $\mathrm{t}^{25}$ and there is much room for unintended but non-deceitful errors in describing or recounting various aspects of an event. Mental chronometry is a complex interplay of perception and response. The perceptions of the officer involved in a high threat situation may not be recalled with complete accuracy by that officer.

\section{Conclusion}

Memory is not a recording device with the same fidelity or playback capabilities as a mechanical recorder. Complexity limits our ability to "monitor" multiple stimuli. Subsequent focus on a particular input further limits and eliminates consideration of most or all other environmental activity. In fact, firearms training typically emphasizes sight picture as an officers main focus in confronting a threat, though veteran officers and rookies may differ in their efficiency of identifying threats appropriately. ${ }^{26}$ While this adherence to shooting principles is critical in defense, it underscores the point about exclusion of other input outside of the limited sight picture. This inattention blindness (IB) can only be partially mitigated through training and in fact some research suggests even threatening objects elude our attention. ${ }^{27} \mathrm{IB}$ and perceptually salient objects or actions remain important for future study of mental chronometry and the training of officers. Reaction times to perceived threats vary based on a variety of factors. High stress circumstances are further complicated by individual factors such as internal states, physiological and motor performance changes, age, and emotion. Executive functions under high stress do not perform as they do in low stress circumstances. Environmental factors including multiple sensory inputs emanating from critical and trivial sources compound decisional time lag. Inattention blindness and perceptual distortions have real-world implications for the officer faced with perceived threats. Officer action is also evaluated based on circumstances and facts perceived by the officer when selecting, for example, a use of force option. All of these factors can impact not only the decision to utilize deadly force but also the outcome effectiveness of that selection.

Within the law enforcement training community there is currently insufficient attention focused on informing recruit and in-service officers about the causes and effects of reaction time and perceptual misalignment. The conditions discussed in this article have import for the training provided to public safety and military personnel, policy development and implementation, and the knowledge base required for those who investigate serious force usage events. It is recommended that basic recruit academy and in-service training curriculums enhance the scope and depth of topic coverage to better inform officers about the dynamics and effects of perception and stimulus reception, distortions affecting perception and stimulus interpretation, and how these affect reaction time and response selection.

\section{Acknowledgments}

None.

\section{Conflicts of interest}

None.

\section{References}

1. Schmidt RA, Lee TD. Motor learning and performance - 5th edition with web study guide. Human Kinetics. 2014;1-336.

2. Graham v Connor. U.S. Supreme Court. 1989;490(386):396-397.

3. Engel RS, Smith MR. Perceptual distortion and reasonableness during police shootings: law, legitimacy, and future research. Criminology and Public Policy. 2009;8(1):141-151

4. Lewinski W. Biomechanics of lethal force encounters: officer movements. The Police Marksman. 2002;27(6):19-23.

5. Posner MI. Timing the brain: Mental chronometry as a tool in neuroscience. PLoS Biol. 2005;3(2):51.

6. Officer-Involved Shooting Guidelines. Ratified by the IACP Police Psychological Services Section Philadelphia, USA. 2013;1-12.

7. Nieuwenhuys A, Savelsbergh GJ, Oudejans RR. Persistence of threatinduced errors in police officers' shooting decisions. Appl Ergon. 2015;48:263-272.

8. Salinas E, Scerra VE, Hauser CK, et al. Decoupling speed and accuracy in an urgent decision-making task reveals multiple contributions to their trade-off. Front Neurosci. 2014;8(85):1-17.

9. Mlodinow L. Subliminal. USA. 2012.

10. Gladwell M. Blink. Little, Brown and Company, USA. 2005.

11. Lewinski W. Why is the suspect shot in the back? The Police Marksman 2000;20-28.

12. Horstmann G, Ansorge U. Surprise capture and inattentional blindness. Cognition. 2016;157:237-249.

13. Lewinski W, Redmann C. New developments in understanding the behavioral science factors in the "stop shooting" response. Law Enforcement Executive Forum. 2009;9(4):35-54.

14. Bumgarner JB, Lewinski WJ, Hudson W, et al. An examination of police officer mental chronometry: I swear... I don't know how I shot him in the back. The Scene, Journal of the Association for Crime Scene Reconstruction. 2007;1-16.

15. Kahneman D. Thinking fast and slow. Farrar, Straus and Giroux, USA. 2011;1-499.

16. Andersen JP, Pitel M, Weerasinghe A, et al. Highly Realistic Scenario Based Training Simulates the Psychophysiology of Real World Use of Force Encounters: Implications for Improved Police Officer Performance. Journal of Law Enforcement. 2016;5(4):1-14.

17. Novy M. Cognitive distortions during law enforcement shooting. Activitas Nervosa Superior. 2012;54(1-2):1-7.

18. Artwohl A. Perceptual and Memory Distortion During Officer-Involved Shootings. FBI Law Enforcement Bulletin. 2002;71(10):1-18.

19. Taverniers J, Van Ruysseveldt J, Smeets T, et al. High-intensity stress elicits robust cortisol increases, and impairs working memory and visuo-spatial declarative memory and Special Forces candidates: A field experiment Stress. 2010;13(4):323-333.

20. Hope L, Blocksidge D, Gabbert F, et al. Memory and the operational Witness: Police officer recall of firearms encounters as a function of active response role. Law Hum Behav. 2016;40(1):23-25.

21. Chan M, Singhal A. Accident Analysis and Prevention. 2013;50:147-154.

22. Broom MA, Capek AL, Carachi P, et al. Critical phase distractions in anaesthesia and the sterile cockpit concept. Anaesthesia. 2011;66(3):175179 . 
23. Florida Department of Law enforcement, Florida Basic Recruit Training Program - High Liability, USA. 2013.

24. VanHorne P, Riley J A. Left of bang. Black Irish Entertainment, USA 2014.

25. McKinley J, Dempster M, Gormley GJ. 'Sorry, I meant the patient's left side': impact of distraction on left-right discrimination. Med Educ. 2015;49(4):427-435.
26. Vickers JN, Lewinski W. Performing under pressure: Gaze control, decision-making and shooting performance of elite and rookie police officers. Hum Mov Sci. 2012;31(1):101-117.

27. Stothart CR, Wright TJ, Simons DJ, et al. The costs (or benefits) associated with attended objects do little to influence inattentional blindness. Acta Psychol (Amst). 2017;173:101-105. 